\title{
A Trial of the Safety and Efficacy of Chemotherapy Plus Anlotinib vs Chemotherapy Alone as Second- or Third-Line Salvage Treatment for Advanced Non-Small Cell Lung Cancer
}

This article was published in the following Dove Press journal:

Cancer Management and Research

\author{
Hai-ying Wang \\ Jun-feng Chu \\ Yan Zhao \\ Hong Tang \\ Li-li Wang \\ Meng-qiang Zhou \\ Zheng Yan \\ Yan-yan Liu \\ Zhi-hua Yao
}

Department of Internal Medicine, Henan Cancer Hospital or Affiliated Cancer Hospital of Zhengzhou University, Zhengzhou, Henan, People's Republic of China
Correspondence: Zhi-hua Yao Henan Cancer Hospital or Affiliated Cancer Hospital of Zhengzhou University, No. 127 Dongming Road, Zhengzhou, Henan 450008, People's Republic of China Tel +86 37I-6558779I

Email zlyyyaozhihual260@zzu.edu.cn
Purpose: Anlotinib is a newly developed oral multitarget tyrosine kinase inhibitor. We retrospectively evaluated the toxicity and clinical efficacy of chemotherapy combined with anlotinib versus chemotherapy alone for metastatic/advanced non-small cell lung cancer (NSCLC) in patients who failed first- or second-line systemic treatment in China.

Patients and Methods: In this retrospective trial, ninety-four advanced NSCLC patients received chemotherapy combined with anlotinib $(n=41)$ or chemotherapy alone $(n=53)$ in Henan Cancer Hospital. We recorded the objective response rate (ORR), disease control rate (DCR), progression-free survival (PFS) and adverse events (AEs).

Results: In the anlotinib plus chemotherapy group, eleven patients $(27 \%)$ achieved a PR (partial response), and twenty-one patients (51\%) achieved SD (stable disease), with an ORR of $27 \%$ and a DCR of $78 \%$. In the chemotherapy alone group, eight patients $(15 \%)$ achieved a PR, and nineteen patients (36\%) had SD, with an ORR of $15 \%$ and a DCR of $51 \%$. The ORR in the combination arm was slightly, but not obviously, higher than that in the chemotherapy arm $(27 \%$ vs $15 \%, \mathrm{p}>0.05)$. In addition, the DCR was significantly higher in the combination arm than in the chemotherapy alone arm $(78 \%$ vs $51 \%, \mathrm{p}=0.007)$. At the end of follow-up, patients in the combination arm had a 1.5-month longer median PFS than patients in the chemotherapy arm; this difference was statistically significant (5.0 vs 3.5, $\mathrm{p}=0.002$ ). The median OS was not achieved at the final analysis. The hematological and nonhematological toxicities were well tolerated and controlled. In general, most toxicity was limited to grade I or II, well tolerated and controlled.

Conclusion: Our study suggests that anlotinib combined with chemotherapy may be an effective and well-tolerated treatment for advanced NSCLC in patients who fail firstor second-line therapy.

Keywords: anlotinib, chemotherapy, toxicity, efficacy, advanced non-small cell lung cancer

\section{Introduction}

Carcinoma of the lungs is the leading cause of cancer-related death worldwide. ${ }^{1,2}$ NSCLC accounts for approximately $80 \%$ of lung carcinomas. Most NSCLC patients are diagnosed in the middle and advanced stages, and their prognosis is very poor. ${ }^{3}$ Although there have been significant advances in immunotherapy and targeted drugs over the past decade, most patients do not have targeted drug-related mutations, and immune checkpoint inhibitors (ICIs), including nivolumab, pembrolizumab, and atezolizumab, are expensive and not covered by medical insurance. 
Metastatic NSCLC patients without driver genes after standard treatment and patients who fail targeted drug therapy still have a very poor prognosis. ${ }^{4-6}$ New anticancer drugs with improved efficacy and safety are urgently needed, especially for patients who fail second-line treatment and have a good performance status. ${ }^{7,8}$

Tumor growth and metastasis require the sustained support of blood vessels to provide oxygen and nutrients and to expel metabolic waste. Many preclinical trials have suggested that antiangiogenic drugs can reduce the generation of new blood vessels in tumors and promote the normalization of tumor blood vessels, thereby significantly increasing the local drug concentration and enhancing the antitumor activity of drugs. ${ }^{9-11}$ Over the past decade, antiangiogenic treatment has become a particularly important strategy for solid tumors such as colorectal cancer, ${ }^{12}$ hepatocellular cancer, ${ }^{13}$ ovarian cancer ${ }^{14}$ and NSCLC. ${ }^{15}$ Some antiangiogenic agents, such as bevacizumab, ramucirumab and nintedanib, have demonstrated good efficacy in advanced NSCLC. Moreover, the results of many clinical trials suggest that the addition of antiangiogenic drugs to conventional chemotherapy may obviously improve the ORR, PFS and OS of patients with metastatic/advanced NSCLC.

Anlotinib is another potent oral receptor tyrosine kinase inhibitor that targets angiogenesis pathways by inhibiting VEGFR1/2/3, FGFR1/2/3/4, PDGFR $\alpha$ and PDGFR $\beta$. This drug also targets RET, c-Kit and other proteins, thereby inhibiting tumor proliferation. ${ }^{16,17}$ A Phase III trial showed that anlotinib significantly prolongs PFS and OS compared with placebo in patients with advanced/metastatic NSCLC who failed second-line or later salvage therapy. ${ }^{18}$ Although the results are encouraging, the improvement in OS was limited, and the outcome is not satisfactory. Since the combination of antiangiogenic agents and chemotherapy has proven to be a feasible therapeutic strategy in NSCLC, anlotinib plus chemotherapy may show better clinical activity.

Therefore, we carefully conducted a retrospective trial to assess the toxicity and efficacy of anlotinib plus chemotherapy in Chinese patients with metastatic NSCLC who failed first- or second-line treatment.

\section{Patients and Methods}

\section{Patient Characteristics}

Advanced/metastatic NSCLC patients who received chemotherapy combined with anlotinib or chemotherapy alone after first- or second-line treatment in Henan Cancer
Hospital were included in the retrospective trial. If a patient did not progress after 2-4 cycles of combination therapy, he or she was maintained on anlotinib. The other criteria were histologically confirmed advanced/metastatic NSCLC, 18-75 years old, Eastern Cooperative Oncology Group (ECOG) score of 0-2 and adequate liver, bone marrow and kidney function. Exclusion criteria included the following: a small-cell lung cancer (SCLC, including mixed SCLC/NSCLC); clinically significant cardiovascular disease; a symptomatic brain metastases; concomitant cancers; centrally located squamous cell carcinoma with cavitary features; uncontrolled hypertension; and uncontrolled significant comorbid conditions. From April 2014 to October 2019, a total of ninety-four advanced NSCLC patients were included in this retrospective trial. We reviewed the medical records and collected sex, age, histologic type, prior therapy, ECOG, treatment toxicity, laboratory data and imaging data from before and after each cycle.

The Ethics Committee of Henan Cancer Hospital approved our trial. Before receiving combination treatment, all NSCLC patients provided written informed consent. All the procedures in this trial are in full compliance with the Declaration of Helsinki.

\section{Treatment Methods}

Advanced NSCLC patients received anlotinib plus chemotherapy or chemotherapy alone after first- or secondline treatment. If the patient did not progress after 2-4 cycles of combination therapy, he or she was maintained on anlotinib. Anlotinib was initially administered orally $12 \mathrm{mg}$ daily for 14 days and then discontinued for 7 days (3-week cycle).

\section{Safety and Outcome Assessments}

Treatment effects were assessed by computed tomography scans every two cycles based on response evaluation criteria in solid tumors (RECIST 1.1). The DCR was defined as the total percentage of patients with a complete response (CR), a PR and SD. In addition, we assessed treatment-related AEs based on the Common Terminology Criteria for Adverse Events (CTCAE) version 4.03. PFS was defined from the beginning of combination treatment to tumor progression or death from any cause.

\section{Statistical Analysis}

We analyzed all statistical data with SPSS software (version 14.0). The descriptive variables relating to treatmentrelated toxicity and patient characteristics were directly 
calculated from the database. In order to compare toxicities and response in the two groups, $\chi 2$ test and Fisher's exact test were employed. Meanwhile, PFS was calculated from the first day of treatment to the date of progressive disease or the date of death from any causes. The median PFS was computed by making use of Kaplan-Meier methods and compared by means of the Log-rank test. A P-value of 0.05 (two-sided) was considered to be statistically significant.

\section{Results}

\section{Patient Characteristics}

The baseline characteristics of the advanced NSCLC patients, including age, gender, ECOG score, histological subtype, surgical history, radiotherapy history, first-line bevacizumab treatment, second- and third-line treatment, chemotherapy regimen, brain metastasis and EGFR status, are summarized in Table 1. The characteristics of the patients in the two groups were roughly similar. Thirtyeight patients (40\%) were female, and fifty-six (60\%) were male. The average patient age was 56 years (range, 33-75 years). The pathological types included adenocarcinoma $(66 \%, 62 / 94)$ and squamous cell carcinoma (34\%, 32/94). Eighteen percent of the patients (17/94) had a surgical history, 14\% (13/94) had a history of radiotherapy, and $23 \%(22 / 94)$ had a history of first-line bevacizumab treatment. A total of 41 advanced NSCLC patients underwent treatment with anlotinib in combination with chemotherapy, $23(56 \%, 23 / 41)$ as second-line combination treatment and $18(44 \%, 18 / 41)$ as third-line treatment. The chemotherapy regimens were docetaxel-based, gemcitabinebased, vinorelbine-based or pemetrexed-based every 21 days. The dose of chemotherapy drugs is the standard dose. Nonprogressive patients received anlotinib maintenance therapy after 2-4 cycles of combined treatment.

\section{Efficacy}

Although none of the 41 patients in the anlotinib plus chemotherapy group achieved a CR, 11 showed a PR, and 21 had SD. The ORR was $27 \%$, and the DCR was $78 \%$ (Table 2). Nineteen patients entered the anlotinib maintenance treatment. The median PFS was 5.0 months (Table 3; 95\% CI, 4.18-5.82). In the chemotherapy group, the ORR was $15 \%$, the DCR was $51 \%$, and the median PFS was 3.5 months (Tables 2 and 3; 95\% CI, 3.11-3.89). Only 5 patients entered the chemotherapy maintenance treatment. The ORR was slightly, but not
Table I Patient Baseline Characteristics

\begin{tabular}{|c|c|c|c|}
\hline \multirow[t]{2}{*}{$\begin{array}{l}\text { Baseline } \\
\text { Characteristics }\end{array}$} & $\begin{array}{l}\text { Chemotherapy } \\
\text { Plus Anlotinib } \\
(n=4 I)\end{array}$ & $\begin{array}{l}\text { Chemotherapy } \\
(n=53)\end{array}$ & \multirow[t]{2}{*}{ p-value } \\
\hline & $\begin{array}{l}\text { No. of Patients } \\
\text { (\%) }\end{array}$ & $\begin{array}{l}\text { No. of Patients } \\
\text { (\%) }\end{array}$ & \\
\hline $\begin{array}{l}\text { Age } \\
\text { Median } \\
\text { Range } \\
<60 \\
\geq 60\end{array}$ & $\begin{array}{l}52 \\
33-75 \\
31(76 \%) \\
10(24 \%)\end{array}$ & $\begin{array}{l}58 \\
34-75 \\
38(72 \%) \\
15(28 \%)\end{array}$ & 0.670 \\
\hline $\begin{array}{l}\text { Gender (sex) } \\
\text { Men } \\
\text { Women }\end{array}$ & $\begin{array}{l}23(56 \%) \\
18(44 \%)\end{array}$ & $\begin{array}{l}33(62 \%) \\
20(38 \%)\end{array}$ & 0.546 \\
\hline $\begin{array}{l}\text { ECOG } \\
\text { performance status } \\
0 \\
1 \\
2\end{array}$ & $\begin{array}{l}17(42 \%) \\
19(46 \%) \\
5(12 \%)\end{array}$ & $\begin{array}{l}20(38 \%) \\
26(49 \%) \\
7(13 \%)\end{array}$ & 0.934 \\
\hline $\begin{array}{l}\text { Histology } \\
\text { Adenocarcinoma } \\
\text { Squamous-cell } \\
\text { carcinoma }\end{array}$ & $\begin{array}{l}28(68 \%) \\
13(32 \%)\end{array}$ & $\begin{array}{l}34(64 \%) \\
19(36 \%)\end{array}$ & 0.674 \\
\hline $\begin{array}{l}\text { Previous surgery } \\
\text { Yes } \\
\text { No }\end{array}$ & $\begin{array}{l}8(20 \%) \\
33(80 \%)\end{array}$ & $\begin{array}{l}9(17 \%) \\
44(83 \%)\end{array}$ & 0.752 \\
\hline $\begin{array}{l}\text { Previous } \\
\text { radiotherapy } \\
\text { Yes } \\
\text { No }\end{array}$ & $\begin{array}{l}5(12 \%) \\
36(88 \%)\end{array}$ & $\begin{array}{l}8(15 \%) \\
45(85 \%)\end{array}$ & 0.686 \\
\hline $\begin{array}{l}\text { First-line } \\
\text { bevacizumab } \\
\text { Yes } \\
\text { No }\end{array}$ & $\begin{array}{l}9(22 \%) \\
32(78 \%)\end{array}$ & $\begin{array}{l}13(25 \%) \\
40(75 \%)\end{array}$ & 0.770 \\
\hline $\begin{array}{l}\text { Second-line } \\
\text { treatment } \\
\text { Third-line } \\
\text { treatment }\end{array}$ & $\begin{array}{l}23(56 \%) \\
18(44 \%)\end{array}$ & $\begin{array}{l}33(62 \%) \\
20(38 \%)\end{array}$ & 0.546 \\
\hline $\begin{array}{l}\text { Combination } \\
\text { chemotherapy } \\
\text { regimen } \\
\text { Docetaxel based } \\
\text { Gemcitabine } \\
\text { based } \\
\text { Vinorelbine } \\
\text { based } \\
\text { Pemetrexed } \\
\text { based }\end{array}$ & $\begin{array}{l}15(37 \%) \\
7(17 \%) \\
9(22 \%) \\
10(24 \%)\end{array}$ & $\begin{array}{l}23(43 \%) \\
11(21 \%) \\
13(25 \%) \\
6(11 \%)\end{array}$ & 0.421 \\
\hline $\begin{array}{l}\text { EGFR status } \\
\text { Wild type }\end{array}$ & $20(49 \%)$ & $24(45 \%)$ & 0.935 \\
\hline
\end{tabular}

(Continued) 
Table I (Continued).

\begin{tabular}{|c|c|c|c|}
\hline \multirow[t]{2}{*}{$\begin{array}{l}\text { Baseline } \\
\text { Characteristics }\end{array}$} & $\begin{array}{l}\text { Chemotherapy } \\
\text { Plus Anlotinib } \\
(n=4 I)\end{array}$ & $\begin{array}{l}\text { Chemotherapy } \\
(n=53)\end{array}$ & \multirow[t]{2}{*}{ p-value } \\
\hline & $\begin{array}{l}\text { No. of Patients } \\
\text { (\%) }\end{array}$ & $\begin{array}{l}\text { No. of Patients } \\
\text { (\%) }\end{array}$ & \\
\hline $\begin{array}{l}\text { Mutant } \\
\text { Unknown }\end{array}$ & $\begin{array}{l}17(41 \%) \\
4(10 \%)\end{array}$ & $\begin{array}{l}23(44 \%) \\
6(11 \%)\end{array}$ & \\
\hline $\begin{array}{l}\text { Brain metastasis } \\
\text { Yes } \\
\text { No }\end{array}$ & $\begin{array}{l}13(32 \%) \\
28(68 \%)\end{array}$ & $\begin{array}{l}15(28 \%) \\
38(72 \%)\end{array}$ & 0.720 \\
\hline
\end{tabular}

Abbreviation: ECOG, Eastern Cooperative Oncology Group.

Table 2 Overall Response to Treatment

\begin{tabular}{|c|c|c|c|c|c|}
\hline \multirow[t]{2}{*}{$\begin{array}{l}\text { Tumor } \\
\text { Response }\end{array}$} & \multicolumn{2}{|c|}{$\begin{array}{l}\text { Chemotherapy } \\
\text { Plus Anlotinib } \\
(n=4 I)\end{array}$} & \multicolumn{2}{|c|}{$\begin{array}{l}\text { Chemotherapy } \\
(n=53)\end{array}$} & \multirow[t]{2}{*}{ P-value } \\
\hline & No. & $\%$ & No. & $\%$ & \\
\hline $\begin{array}{l}\text { Complete } \\
\text { response }\end{array}$ & 0 & 0 & 0 & 0 & \\
\hline $\begin{array}{l}\text { Partial } \\
\text { response }\end{array}$ & II & 27 & 8 & 15 & \\
\hline Stable disease & 21 & 51 & 19 & 36 & \\
\hline $\begin{array}{l}\text { Progressive } \\
\text { disease }\end{array}$ & 9 & 22 & 26 & 49 & \\
\hline $\mathrm{RR}$ & II & 27 & 8 & 15 & 0.160 \\
\hline DCR & 32 & 78 & 27 & 51 & 0.007 \\
\hline
\end{tabular}

Abbreviations: $\mathrm{RR}$, response rate; $\mathrm{DCR}$, disease control rate.

Table 3 Kaplan-Meier Analysis

\begin{tabular}{|l|l|l|l|}
\hline & $\begin{array}{l}\text { Chemotherapy } \\
\text { Plus Anlotinib } \\
(\mathbf{9 5 \%} \mathbf{~ C l})\end{array}$ & $\begin{array}{l}\text { Chemotherapy } \\
(\mathbf{9 5 \%} \text { Cl) }\end{array}$ & $\begin{array}{l}\text { p-value } \\
\text { (Log } \\
\text { Rank) }\end{array}$ \\
\hline $\begin{array}{l}\text { PFS } \\
\text { (months) }\end{array}$ & $5.0(4.18-5.82)$ & $3.5(3.1 \mathrm{I}-3.89)$ & 0.002 \\
\hline
\end{tabular}

Abbreviations: PFS, progression-free survival; OS, overall survival.

obviously, higher in the combination arm than in the chemotherapy arm (Table $2 ; 27 \%$ vs $15 \%, \mathrm{p}=0.16$ ). The DCR was obviously higher in the combination arm than in the chemotherapy arm (Table 2; 78\% vs $51 \%$, $\mathrm{p}=0.007$ ). The median follow-up period was 10 months. At the end of follow-up, a considerable improvement in median PFS (Table 3, Figure 1; 5.0 vs $3.5, \mathrm{p}=0.002$ ) was observed in the combination arm compared to the chemotherapy alone arm. The median OS was not achieved at the final analysis.

\section{Adverse Events}

The toxicity profiles of the two regimens are summarized in Table 4. No treatment-associated mortalities occurred. The following AEs were obviously more frequent in the combination arm than in the chemotherapy arm: leukopenia $(63 \%$ vs $57 \%)$, thrombocytopenia $(24 \%$ vs $19 \%)$, anorexia ( $51 \%$ vs $46 \%$ ), nausea ( $51 \%$ vs $36 \%$ ), diarrhea (12\% vs $6 \%)$, increased triglycerides (17\% vs $15 \%)$, fatigue ( $46 \%$ vs $36 \%$ ), creatinine ( $10 \%$ vs $8 \%$ ), proteinuria ( $12 \%$ vs $4 \%$ ), hypertension ( $42 \%$ vs $11 \%$ ), handfoot skin reaction (HFSR, $22 \%$ vs $0 \%$ ), hemoptysis $(12 \%$ vs $4 \%$ ), hypothyroidism ( $27 \%$ vs $0 \%$ ), hoarse ( $7 \%$ vs $2 \%)$, and rash (5\% vs $2 \%)$. Among these AEs, the combination arm recorded more events, including hypertension, hand-foot skin reaction, and hypothyroidism, than did the chemotherapy alone arm (all $\mathrm{P}<0.05$ ). Although myelosuppression and gastrointestinal reactions were the most common grade III or IV toxicities in the combination group, there were no obvious differences between the two arms (all $\mathrm{P}>0.05$ ). In general, most toxicity was limited to grade I or II, well tolerated and controlled.

All patients in the combination group began anlotinib treatment at $12 \mathrm{mg} /$ day. Two patients had a dose reduction to $10 \mathrm{mg}$ daily due to HFSR. The most frequent adverse events on anlotinib maintenance therapy were hypertension, hand-foot skin reaction, increased triglycerides, hypothyroidism, proteinuria and fatigue, most of which were grade I or II and consistent with a prior report on a Phase II/III study of anlotinib. No patients stopped anlotinib treatment due to side effects during maintenance therapy.

\section{Discussion}

Angiogenesis is an important feature of cancer, and antiangiogenic therapy plays an increasingly crucial role in advanced/metastatic NSCLC. Many clinical studies have demonstrated that bevacizumab plus chemotherapy significantly prolongs PFS and OS compared to chemotherapy alone in patients with advanced non-squamous NSCLC and colon, breast, renal, and ovarian cancer. ${ }^{19}$ Since a 2-month OS benefit was shown in the LUME-Lung 1 trial, the European Medicines Agency (EMA) approved docetaxel combined with nintedanib for advanced/metastatic NSCLC patients with adenocarcinoma in $2014 .^{20}$ In another Phase III trial, ramucirumab plus docetaxel significantly prolonged PFS and OS compared with 


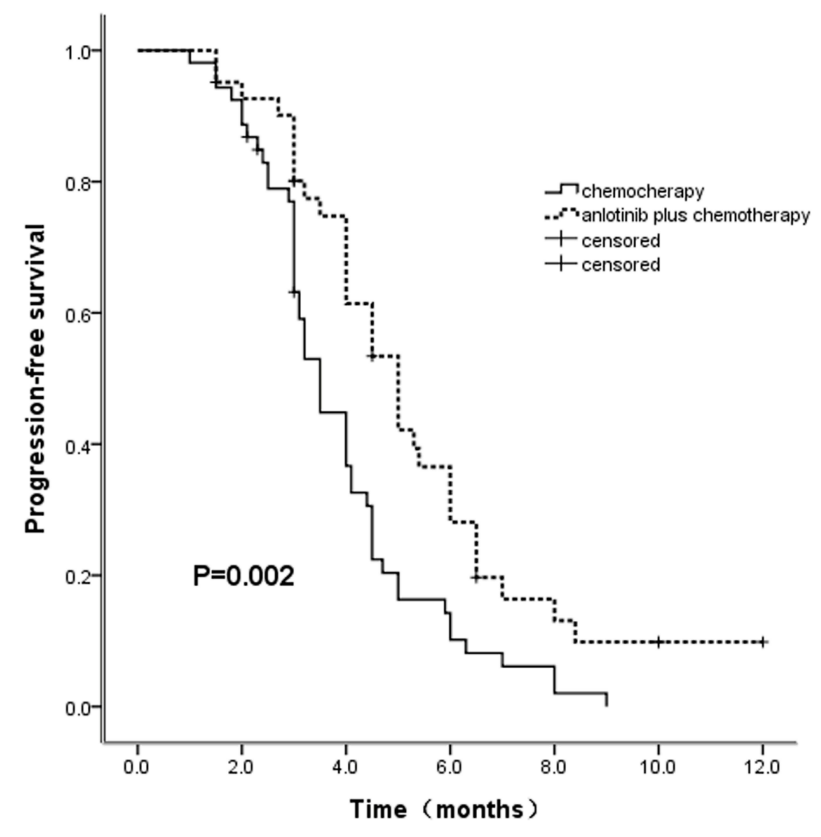

Figure I Progression-free survival by treatment arm (Kaplan-Meier curve).

docetaxel only in patients with any pathologic subtype of advanced NSCLC who progressed after platinum-based treatment. ${ }^{21}$ A series of retrospective and prospective clinical studies showed that the combination of apatinib and chemotherapy in refractory NSCLC had a tendency of a higher ORR and DCR and prolonged OS. ${ }^{22,23}$ Data from a previous meta-analysis consistently showed that the addition of antiangiogenic drugs to chemotherapy increased PFS and the ORR, but the benefits on OS in advanced NSCLC have not been consistent.

Anlotinib also has encouraging antitumor effects and acceptable toxicity in advanced NSCLC, small cell lung carcinoma, medullary thyroid cancer, soft tissue sarcomas and metastatic renal clear cell cancer. ${ }^{24-28}$ A multicenter, double-blind, Phase III randomized clinical trial (ALTER 0303) of patients with advanced NSCLC who progressed after second-line or later treatment showed that compared with the placebo group, the anlotinib group had a significantly longer PFS (5.4 vs 1.4 months; $\mathrm{P}<0.001$ ) and OS (9.6 vs 6.3 months; $\mathrm{P}<0.001)$ and a higher ORR (9.2\% vs $0.7 \% ; \mathrm{P}<0.001)$ and DCR $(81.0 \%$ vs $37.1 \%$; $\mathrm{P}<$ $0.001) .{ }^{18}$ As a novel multitargeted kinase inhibitor, anlotinib, which inhibits not only tumor cell proliferation but also tumor angiogenesis, is the first drug approved in China as third-line therapy for metastatic/advanced NSCLC. However, drug resistance eventually emerged, and the improvement in OS was finite. The combination of anlotinib to chemotherapy may be more effective and delay the development of drug resistance. Moreover, the

Table 4 Toxicity Profile

\begin{tabular}{|c|c|c|c|c|c|}
\hline \multirow{3}{*}{$\begin{array}{l}\text { Toxicity } \\
\text { Grade }\end{array}$} & \multicolumn{4}{|c|}{ Number of Patients, n (\%) } & \multirow[t]{3}{*}{ P-value } \\
\hline & \multicolumn{2}{|c|}{ Chemotherapy Plus Anlotinib $(n=4 I)$} & \multicolumn{2}{|c|}{ Chemotherapy $(n=53)$} & \\
\hline & I + II & III+ IV & I+ II & III+ IV & \\
\hline \multicolumn{6}{|l|}{ Haematological toxicity } \\
\hline Leukopenia & $17(41)$ & $9(22)$ & $20(38)$ & $10(19)$ & 0.796 \\
\hline Thrombocytopenia & $7(17)$ & $3(7)$ & $6(11)$ & $4(8)$ & 0.725 \\
\hline Anemia & $19(46)$ & $5(12)$ & $27(51)$ & $8(15)$ & 0.270 \\
\hline \multicolumn{6}{|l|}{ Non-haematological toxicity } \\
\hline Anorexia & $20(49)$ & I (2) & $21(40)$ & $3(6)$ & 0.559 \\
\hline Nausea/vomiting & $20(49)$ & I (2) & $19(36)$ & $0(0)$ & 0.204 \\
\hline Diarrhea & $3(7)$ & $2(5)$ & $2(4)$ & $I(2)$ & 0.522 \\
\hline Triglyceride elevation & $7(17)$ & $0(0)$ & $8(15)$ & $0(0)$ & 0.123 \\
\hline Fatigue & $18(44)$ & I (2) & $16(30)$ & $3(6)$ & 0.334 \\
\hline Creatinine & $4(10)$ & $0(0)$ & $3(6)$ & I (2) & 0.514 \\
\hline Proteinuria & $5(12)$ & $0(0)$ & $2(4)$ & $0(0)$ & 0.123 \\
\hline ALT/AST & $10(24)$ & $2(5)$ & $15(28)$ & $4(8)$ & 0.763 \\
\hline Hypertension & $15(37)$ & $2(5)$ & $6(11)$ & $0(0)$ & 0.003 \\
\hline Hand-foot skin reaction & $8(20)$ & I (2) & $0(0)$ & $0(0)$ & 0.002 \\
\hline Haemoptysis & $5(12)$ & $0(0)$ & $2(4)$ & $0(0)$ & 0.123 \\
\hline Hypothyroidism & II (27) & $0(0)$ & $0(0)$ & $0(0)$ & 0.000 \\
\hline Hoarse & $3(7)$ & $0(0)$ & I (2) & $0(0)$ & 0.196 \\
\hline Rash & $2(5)$ & $0(0)$ & I (2) & $0(0)$ & 0.413 \\
\hline
\end{tabular}


adverse reactions to chemotherapy and anlotinib are different, and many clinical trials have shown that anlotinib has mild toxicity and is well tolerated. Therefore, anlotinib plus chemotherapy is a possible treatment option for metastatic NSCLC patients.

To our knowledge, there have been few trials of chemotherapy combined with anlotinib for metastatic NSCLC patients. This is the first retrospective study of chemotherapy combined with anlotinib versus chemotherapy only for refractory NSCLC patients. Our study showed that this well-tolerated combination had clinical activity in advanced NSCLC as a second- or third-line treatment. In the anlotinib plus chemotherapy arm, the ORR and DCR were $27 \%$ and $78 \%$, respectively, and the median PFS was 5.0 months. In the chemotherapy arm, the ORR was $15 \%$, the DCR was $51 \%$, and the median PFS was 3.5 months (Tables 2 and 3; 95\% CI, 3.11-3.89). The ORR of the combination treatment was higher than that of chemotherapy alone (Table 2; 27\% vs $15 \%, p=0.16$ ). The DCR was obviously higher in the combination arm than in the chemotherapy arm (Table 2; $78 \%$ vs $51 \%, \mathrm{p}=0.007$ ). The median follow-up period was 10 months. At the end of follow-up, a considerable improvement in median PFS (Table 3, Figure 1; 5.0 vs $3.5, \mathrm{p}=0.002$ ) was observed in the combination arm compared to the chemotherapy alone arm. The median OS was not achieved at the final analysis. Our findings showed obvious improvements in the DCR and PFS with the addition of anlotinib to chemotherapy in refractory NSCLC. Our study also showed a much higher ORR and DCR and a longer PFS than has been reported for ramucirumab, nintedanib and apatinib combination..$^{20-22}$ The metastasis of cancer cells is a very complicated process, which mainly depends on the invasion and migration ability of malignant tumor cells. Malignant tumor cells need more oxygen and nutrients to maintain growth and rapidly developing tumors will be more likely to depend on new blood vessels. Our results may be because that all the target molecules of anlotinib contribute to inhibit tumor angiogenesis and partial tumor cell growth function. On the other hand, this is due to the effect of VEGF inhibition favoring the effect of chemotherapy, and the combination maximizes the efficacy when the toxicity of anlotinib is mild and well tolerated.

The following AEs were more frequent in the combination arm than in the chemotherapy only arm: leukopenia (63\% vs 57\%), thrombocytopenia (24\% vs 19\%), anorexia ( $51 \%$ vs $46 \%$ ), nausea ( $51 \%$ vs $36 \%$ ), diarrhea ( $12 \%$ vs $6 \%$ ), increased triglycerides ( $17 \%$ vs $15 \%$ ), fatigue ( $46 \%$ vs $36 \%$ ), creatinine $(10 \%$ vs $8 \%)$, proteinuria $(12 \%$ vs $4 \%)$, hypertension ( $42 \%$ vs 11\%), hand-foot skin reaction (HFSR, $22 \%$ vs $0 \%$ ), hemoptysis ( $12 \%$ vs $4 \%$ ), hypothyroidism $(27 \%$ vs $0 \%)$, hoarse ( $7 \%$ vs $2 \%$ ), and rash ( $5 \%$ vs $2 \%$ ). Compared with the chemotherapy alone group, the combination treatment group had more events, including hypertension, hand-foot skin reaction, and hypothyroidism $(\mathrm{P}<0.05)$; there was no significant difference between groups in the remaining AEs $(\mathrm{P}>0.05)$. Although myelosuppression and gastrointestinal reactions were the most common grade III/ IV AEs in the combination group, there was no obvious difference between the two arms (all $\mathrm{P}>0.05$ ). In general, most toxicity was limited to grade I or II, well tolerated and controlled. The most frequent AEs on anlotinib maintenance therapy were hypertension, hand-foot skin reaction, increased triglycerides, hypothyroidism, proteinuria and fatigue, most of which were grade I or II and consistent with the results of a Phase II/III trial of anlotinib. All patients in the combination group began anlotinib treatment at $12 \mathrm{mg} /$ day. Two patients had a dose reduction to $10 \mathrm{mg}$ daily for HFSR. No patient stopped anlotinib treatment due to side effects during maintenance therapy.

However, there are some limitations of this study. First, it had a relatively small sample size and a retrospective design. Second, potential predictive biomarkers were not reported. Third, QoL (quality of life) was not evaluated. Finally, although our study was retrospective, we carefully analyzed the baseline characteristics of the patients and found no significant differences, which somewhat increased the accuracy of the comparison between the two arms.

\section{Conclusion}

In conclusion, chemotherapy plus anlotinib combined with anlotinib maintenance may be a reliable, safe and feasible treatment strategy for advanced NSCLC patients who fail first- or second-line treatment. Based on clinical evidence supporting the use of chemotherapy plus antiangiogenic drugs and the accumulation of clinical experience, many ongoing prospective clinical trials are evaluating the toxicity and efficacy of anlotinib plus chemotherapy in NSCLC patients as first- or second-line treatment. It is hopeful that anlotinib plus chemotherapy will be used as salvage therapy for patients with metastatic/advanced NSCLC in the future.

\section{Ethics}

This study was approved by the Ethics Committee of Henan Cancer Hospital. All procedures performed in studies involving human participants were in accordance with 
the ethical standards of the institutional and/or national research committee and with the Declaration of Helsinki. The requirement for informed consent was waived as this was a retrospective study.

\section{Disclosure}

The authors report no conflicts of interest in this work.

\section{References}

1. Jemal A, Bray F, Center MM, Ferlay J, Ward E, Forman D. Global cancer statistics. CA Cancer J Clin. 2011;61(2):69-90. doi:10.3322/ caac. 20107

2. Lu J, Han B. Liquid biopsy promotes non-small cell lung cancer precision therapy. Technol Cancer Res Treat. 2018;17:1533033818801809. doi:10.1177/1533033818801809

3. Siegel RL, Miller KD, Jemal A. Cancer statistics, 2018. CA Cancer J Clin. 2018;68(1):7-30. doi:10.3322/caac.21442

4. Reck M, Rodriguez-Abreu D, Robinson AG, et al. Updated analysis of KEYNOTE-024: pembrolizumab versus platinum-based chemotherapy for advanced non-small-cell lung cancer with PD-L1 tumor proportion score of $50 \%$ or greater. $J$ clin oncol. 2019;37 (7):537-546. doi:10.1200/JCO.18.00149

5. Shaw AT, Dong-Wan K, Kazuhiko N, et al. Crizotinib versus chemotherapy in advanced ALK-positive lung cancer. $N$ Engl $\mathrm{J}$ Med. 2013;368(25):2385-2394. doi:10.1056/NEJMoa1214886

6. Mok TS, Wu YS. Gefitinib or carboplatin-paclitaxel in pulmonary adenocarcinoma. J Evid Based Med. 2009;361(10):947.

7. Ettinger DS, Aisner DL, Wood DE, et al. NCCN guidelines insights: non-small cell lung cancer, version 5.2018. J Natl Compr Canc Netw. 2018;16(7):807-821. doi:10.6004/jnccn.2018.0062

8. Ettinger DS, Wood DE, Aisner DL, et al. Non-small cell lung cancer, version 5.2017, NCCN clinical practice guidelines in oncology. $J$ Natl Compr Canc Netw. 2017;15(4):504-535. doi:10.6004/jnccn.2017.0050

9. Tolaney SM, Yves B, Duda DG, et al. Role of vascular density and normalization in response to neoadjuvant bevacizumab and chemotherapy in breast cancer patients. Proc Natl Acad Sci U S A. 2015;112(46):201518808. doi:10.1073/pnas. 1518808112

10. Batchelor TT, Sorensen AG, Tomaso ED, et al. AZD2171, a Pan-VEGF receptor tyrosine kinase inhibitor, normalizes tumor vasculature and alleviates edema in glioblastoma patients. Cancer Cell. 2007;11(1):83-95. doi:10.1016/j.ccr.2006.11.021

11. Sorensen AG, Batchelor TT, Zhang WT, et al. A "vascular normalization index" as potential mechanistic biomarker to predict survival after a single dose of cediranib in recurrent glioblastoma patients. Cancer Res. 2009;69(13):5296-5300. doi:10.1158/0008-5472.CAN-09-0814

12. Tomasello G, Petrelli F, Ghidini M, Russo A, Passalacqua R, Barni S. FOLFOXIRI plus bevacizumab as conversion therapy for patients with initially unresectable metastatic colorectal cancer: a systematic review and pooled analysis. JAMA oncol. 2017;3(7):e170278. doi:10.1001/jamaoncol.2017.0278

13. Bruix J, Qin S, Merle P, et al. Regorafenib for patients with hepatocellular carcinoma who progressed on sorafenib treatment (RESORCE): a randomised, double-blind, placebo-controlled, Phase 3 trial. Lancet. 2017;389(10064):56-66. doi:10.1016/S0140-6736(16)32453-9
14. Komiyama S, Kato K, Inokuchi Y, et al. Bevacizumab combined with platinum-taxane chemotherapy as first-line treatment for advanced ovarian cancer: a prospective observational study of safety and efficacy in Japanese patients (JGOG3022 trial). Int J Clin Oncol. 2019;24(1):103-114. doi:10.1007/s10147-018-1319-y

15. Sandler A, Gray R, Perry MC, et al. Paclitaxel-carboplatin alone or with bevacizumab for non-small-cell lung cancer. $N$ Engl $J$ Med. 2006;355(24):2542-2550. doi:10.1056/NEJMoa061884

16. Lin B, Song X, Yang D, Bai D, Yao Y, Lu N. Anlotinib inhibits angiogenesis via suppressing the activation of VEGFR2, PDGFR $\beta$ and FGFR1. Gene. 2018;654:S0378111918301550. doi:10.1016/j.gene.2018.02.026

17. Sun Y, Wei N, Feng D, et al. Safety, pharmacokinetics, and antitumor properties of anlotinib, an oral multi-target tyrosine kinase inhibitor, in patients with advanced refractory solid tumors. $J$ Hematol Oncol. 2016;9(1):105. doi:10.1186/s13045-016-0332-8

18. Han B, Li K, Wang Q, et al. Effect of anlotinib as a third-line or further treatment on overall survival of patients with advanced non-small cell lung cancer: the ALTER 0303 phase 3 randomized clinical trial. JAMA oncol. 2018;4(11):1569-1575. doi:10.1001/jamaoncol.2018.3039

19. Caicun Z, Yi-Long W, Gongyan C, et al. BEYOND: a randomized, double-blind, placebo-controlled, multicenter, phase III study of first-line carboplatin/paclitaxel plus bevacizumab or placebo in Chinese patients with advanced or recurrent nonsquamous non-smallcell lung cancer. $J$ clin oncol. 2015;33(19):2197-2204. doi:10.1200/ JCO.2014.59.4424

20. Reck M, Kaiser R, Mellemgaard A, et al. Docetaxel plus nintedanib versus docetaxel plus placebo in patients with previously treated non-small-cell lung cancer (LUME-Lung 1): a phase 3, double-blind, randomised controlled trial. Lancet Oncol. 2014;15 (2):143-155. doi:10.1016/S1470-2045(13)70586-2

21. Garon EB, Ciuleanu T-E, Arrieta O, et al. Ramucirumab plus docetaxel versus placebo plus docetaxel for second-line treatment of stage IV non-small-cell lung cancer after disease progression on platinum-based therapy (REVEL): a multicentre, double-blind, randomised phase 3 trial. Lancet. 2014;384(9944):665-673. doi:10.1016/S0140-6736(14)60845-X

22. Tang J, Li XY, Liang JB, Wu PL, Li X. Apatinib plus chemotherapy shows clinical activity in advanced NSCLC: a retrospective study. Oncol Res. 2019;27(6):635-641. doi:10.3727/096504018X15288447760357

23. Wu D, Liang L, Nie L, et al. Efficacy, safety and predictive indicators of apatinib after multilines treatment in advanced nonsquamous nonsmall cell lung cancer: apatinib treatment in nonsquamous NSCLC. Asia Pac J Clin Oncol. 2018;14(6):446-452.

24. Yang $\mathrm{S}$, Zhang Z, Wang Q. Emerging therapies for small cell lung cancer. J Hematol Oncol. 2019;12(1):47. doi:10.1186/s13045-019-0736-3

25. Zhou AP, Bai Y, Song Y, et al. Anlotinib versus sunitinib as first-line treatment for metastatic renal cell carcinoma: a randomized phase II clinical trial. Oncologist. 2019;24(8):e702-e708. doi:10.1634/theoncologist.2018-0839

26. Han B, Li K, Zhao Y, et al. Anlotinib as a third-line therapy in patients with refractory advanced non-small-cell lung cancer: a multicentre, randomised phase II trial (ALTER0302). $\mathrm{Br}$ J Cancer. 2018;118(5):654-661. doi:10.1038/bjc.2017.478

27. Sun Y, Du F, Gao M, et al. Anlotinib for the treatment of patients with locally advanced or metastatic medullary thyroid cancer. Thyroid. 2018;28(11):1455-1461. doi:10.1089/thy.2018.0022

28. Wang H, Chu J, Zhang P, et al. Safety and efficacy of chemotherapy combined with anlotinib plus anlotinib maintenance in Chinese patients with advanced/metastatic soft tissue sarcoma. Onco Targets Ther. 2020;13:1561-1568. doi:10.2147/OTT.S235349 


\section{Publish your work in this journal}

Cancer Management and Research is an international, peer-reviewed open access journal focusing on cancer research and the optimal use of preventative and integrated treatment interventions to achieve improved outcomes, enhanced survival and quality of life for the cancer patient.
The manuscript management system is completely online and includes a very quick and fair peer-review system, which is all easy to use. Visit http://www.dovepress.com/testimonials.php to read real quotes from published authors.

Submit your manuscript here: https://www.dovepress.com/cancer-management-and-research-journal 